\title{
El poder para dominar, una estupidez humana.
}

\section{The power to dominate, a human stupidity.}

DOI: 10.32870/sincronia.axxv.n80.1b21

\author{
Juan Diego Ortiz Acosta \\ Departamento de Filosofía. Universidad de Guadalajara. (MÉXICO) \\ CE: jdiego_ortiz@hotmail.com / ID ORCID: 0000-0001-7543-0468
}

Esta obra está bajo una Licencia Creative Commons Atribución-NoComercial 4.0 Internacional

Recibido: 18/01/2021

Revisado: 30/04/2021

Aprobado: 16/06/2021

\section{RESUMEN}

El poder para dominar siempre ha sido un deseo y una aspiración humana que muchos han conquistado y ejercido a través del tiempo. Se trata de una cultura de la avaricia que no tiene consideraciones hacia los demás porque lo que busca es la acumulación, el control y el prestigio, causando sufrimiento y devastación. El poder dominante se ejerce desde macroestructuras económicas y políticas, como también desde microestructuras sociales, ya que el control y el abuso hacia los otros también lo podemos observar en todo tipo de relaciones sociales. A este poder, aquí lo denominamos poder-sobre, el cual ha sido estudiado, legitimado y cuestionado desde la filosofía política y las ciencias sociales. En este caso se recurre a autores clásicos y contemporáneos, quienes han debatido sobre este problema político. En el artículo se analiza parte de esa teoría y se asocia el poder para dominar como un acto de estupidez porque es destructivo y sólo privilegia el interés privado. En el texto se conceptualiza la estupidez y se delimita la discusión porque el problema del poder también tiene otro enfoque, aquel que valida el poder social o colectivo y que tiene fines comunes de emancipación y de creación de una cultura aspiracional de igualdad. Sin embargo, se especifica que el abordaje de la reflexión está centrado en el poder-sobre, ese que sirve para la explotación y el control. En el desarrollo del escrito se documenta que el 
esclavismo, la guerra, la pobreza y la devastación ambiental son consecuencias de ese poder asociado a la estupidez humana.

Palabras clave: Poder. Dominación. Avaricia. Estupidez. Explotación.

\section{ABSTRACT}

The power to dominate has always been a human desire and aspiration that many have conquered and used throughout time. It involves a culture of greed that does not have any considerations towards the others because it only seeks for accumulation, control and prestige, causing suffering and devastation. The power to dominate can be practiced from the economic and political macrostructures, as well as from the social microstructures because control and abuse of the others can be observed in all kinds of social relations. This type of power is defined in this article as "power-over", which has been studied, legitimized and questioned in the social sciences and the political philosophy fields. This paper brings together classical and modern authors who had debated about this political issue for many years. The article analyses part of that theory, describing the power to dominate as a stupidity act because of its destructive potential that only privileges private interest. Also, the concept of stupidity is defined in this text. The issue of power has another approach that validates how social or collective power could also lead to achieving common goals of emancipation or the creation of a culture of equality. This paper, however, focuses the debate on the concept of "power-over" which contributes to exploitation and control. This text highlights how slavery, wars, poverty and environmental issues are consequences of that type of power, which is also linked to human stupidity.

Keywords: Power. Domination. Greed. Stupidity. Exploitation.

\section{Introducción}

El presente trabajo es una reflexión desde el campo de la filosofía política, discusión que pone el acento en analizar el tema del poder como una capacidad de dominación que ejercen ciertos individuos y grupos de interés, produciendo trágicas consecuencias en la vida de la mayoría de las personas y otras especies vivas sobre quienes se ejerce la depredación. En el desarrollo del texto se asevera qué desde la perspectiva del poder como dominación, que también se asocia al control y la explotación, se ha sometido a extensos sectores de las sociedades a condiciones de sufrimiento, y a 
la naturaleza a condiciones de devastación, constituyendo dicho fenómeno una gran estupidez humana porque se atenta contra la vida misma en el planeta. El poder como dominación desata lo peor de la condición humana dando origen a todo tipo de comportamientos perniciosos, como la avaricia, la insolidaridad, la violencia y el egocentrismo, entre otros, constituyendo así una cultura centrada en el interés privado.

Las evidencias históricas y presentes de ese ejercicio de poder son abundantes, las cuales dan testimonio de la autodestrucción de nuestra especie y de la naturaleza misma. Este fenómeno estratificado de dominadores-dominados ha acompañado el devenir humano desde siempre, llegando hoy a un punto insostenible por los daños causados. El poder como dominación lo podemos observar a nivel macroestructural a través del capitalismo y otros sistemas que han existido en el mundo, como el esclavismo, el feudalismo, los imperios, las monarquías, los sistemas religiosos, los fascismos, los comunismos, e incluso en la democracia liberal. Sin embargo, ese poder como dominación también se manifiesta en lo micro social, que tiene que ver con las relaciones cotidianas en la sociedad. Ahí también hay poder y se emplea para controlar, para someter y para crear jerarquías que dominan. Es decir, el problema del poder no está personificado sólo por el estado, el capital, los sistemas de creencias u otras esferas institucionales, sino también por individuos que forman parte del entramado social de cualquier sociedad y que no necesariamente forman parte de macroestructuras económicas o políticas.

Visto así el panorama, se plantea que el poder como dominación es parte de las relaciones sociales y de la cultura, es un problema humano que nos ha llevado a cometer las peores estupideces, desde la guerra, hasta la pobreza, el racismo, el control del otro y la concentración de la riqueza, entre otras tantas imbecilidades. Sin dejar de mencionar la sobreexplotación de mares, bosques, ríos y la desaparición de cientos de especies vivas como resultado de la acción humana. Tenemos pues, que el poder en su sentido destructivo y negativo se ejerce desde grandes estructuras institucionales que siempre están en búsqueda de legitimación, como también es ejercido en toda relación micro social donde unos asumen el rol de dominadores y otros de dominados. La competición por el poder es sin duda una de las mayores huellas en la historia 
humana, como lo señalan Marina y Rambaud (2019) en su obra Biografía de la Humanidad. Historia de la evolución de las culturas.

El estudio de este problema se hace a partir del análisis del concepto de poder desde su acepción negativa autorreferencial, es decir, como dominación a partir de unos intereses individualistas, que como se dijo, el término también es asociado al control, la opresión y explotación. Como es sabido, la filosofía política ha estudiado también el poder desde su versión positiva, es decir, el poder visto como un poder social colectivo que sirve para causas comunes de liberación y emancipación, enfoque que constituye el otro lado de la moneda de esta discusión que lleva siglos. Sin embargo, el interés desde estas líneas es conocer el poder desde la perspectiva autorreferencial de individuos y grupos, ya que es este poder el generador de múltiples crisis existenciales, lo que impulsa a seguir examinando este conflicto para cavilar los trasfondos del problema y plantear las posibilidades de construcción de otras opciones culturales distintas a la dominación. De este modo, el énfasis de la reflexión está puesto en lo que John Holloway (2005) Ilama el poder-sobre, es decir, el poder que se ejerce sobre otros para el control y la dominación.

Un objetivo importante de este análisis es hacer una revisión teórica de algunos autores que han escrito sobre el poder como dominación, esto, para dejar constancia de que ese poder es un problema que cruza la historia humana. A su vez, otra finalidad es exponer diversos fenómenos que son consecuencia del ejercicio del poder opresor, los cuales se reproducen en cada momento histórico y se han convertido en parte de la cultura de nuestra civilización. De igual modo, se reflexiona sobre el concepto de estupidez, ello con la intención de aseverar que las acciones del poder autorreferencial son estupideces que le hacen mucho daño al mundo, pero que, sin embargo, las naturalizamos al considerar que no hay posibilidades de cambiar el destino humano.

El tema del poder es tal vez uno de los asuntos más estudiados en la filosofía y en las ciencias sociales, desde las cuales se han planteado una serie de teorías para explicar su naturaleza, sus fundamentos y sus consecuencias. Desde esos referentes filosóficos y científicos se ha producido una extensa literatura que estudia diversas variables de los procesos de dominación. Algunos autores convergen en sus teorías, mientras otros se contraponen dando lugar a un debate 
que no cesa al respecto. En la mayoría de los posicionamientos teóricos la referencia es el poder político, el cual sigue siendo estudiado con detalle desde diferentes contextos históricos y culturales. A este respecto, es conveniente decir que aquí se aborda el problema del poder como poder político, sin embargo, la especificidad del análisis radica en que se conceptualiza al poder político como un poder que engloba y subyace en el poder económico, militar, eclesial, ideológico, de género y otros tipos que sirven para la dominación. En el entendido que todo proceso social donde se manifiesta opresión, control o explotación es al final de cuentas un asunto con orígenes e implicaciones políticas. Por lo que la dominación estructural y micro social son fenómenos políticos donde se emplea el poder para someter lo público al interés privado. Con lo anterior, no se niega que el poder económico, militar, eclesial, ideológico o de género, tengan sus propias especificidades. La relevancia está en comprender el poder como dominio, sus manifestaciones, causas y alternativas.

\section{El poder como dominación sin más}

En el ejercicio de aproximación para escudriñar el concepto de poder, existen, desde la semántica diversas definiciones, pero son dos las que se revisan en este momento. En el Diccionario de la Lengua Española (2020), de la Real Academia Española se indica que "el poder es la facultad o potencia de hacer algo". Mientras otra definición del mismo diccionario, dice que "el poder es tener más fuerza que alguien, vencerlo luchando cuerpo a cuerpo". En este sentido, la segunda definición es más apropiada para el propósito de estas líneas, ya que se asocia el poder al uso de la fuerza, que históricamente ha sido usada para oprimir. En tanto, el primer significado de poder como facultad o potencia de hacer algo, no se utiliza en este análisis porque es muy genérico, toda vez que, de acuerdo con ese significado, todos tenemos poder porque todos tenemos facultades o potencia para estudiar, trabajar o hacer cualquier otra cosa que nos venga en gana. Esta definición de poder no se asocia a la dominación, opresión o control de otros, sino a la capacidad de hacer que tiene todo ser humano, por lo que esta acepción del término queda rebasada por los acontecimientos 
históricos que han dado origen a conceptualizaciones más profundas sobre el poder, a las cuales se recurre para comprender al poder-sobre los demás.

En esta búsqueda de ampliar y comprender el significado de poder como dominación se acude a autores clásicos como Maquiavelo, Hobbes, Bakunin, Weber, y a otros pensadores contemporáneos como Holloway, Dussel y Foucault, los cuales plantean sus teorías que reafirman la existencia del poder opresor. La referencia a estos autores le da sustento documental al análisis que aquí se expone, sin que ello signifique que la discusión tenga sus límites en esas teorías. Son referentes importantes en la literatura sobre el poder, pero, sin embargo, hay otros muchos filósofos y sociólogos que siguen abordando este problema, a los cuales no se recurre porque el objetivo no es abordar el estado de la cuestión, sino generar una reflexión a partir de ciertos postulados sobre el poder dominante.

Para comenzar con las referencias de estos pensadores tenemos a Nicolás Maquiavelo, quien fue un profundo conocedor de la historia europea. Este autor que escribió El Príncipe señala que, en la mayoría de los imperios, ducados, principados y reinados de su tiempo, y los que le antecedieron, recurrieron a la violencia como medio para hacerse del poder, para conservarlo y para expandirlo, logrando con ello establecer mecanismos de dominación que garantizaron el encumbramiento de reyes y noblezas. El texto de Maquiavelo que data de 1532 ilustra con argumentos históricos el devenir de los estados, de sus emperadores, príncipes y reyes, y su lucha incesante por empoderarse a través de cualquier medio. Para este escritor y diplomático italiano el poder se puede conquistar y conservar por las buenas o por las malas:

Surge de esto una cuestión: si vale más ser amado que temido, o temido que amado. Nada mejor que ser ambas cosas a la vez; pero puesto que es difícil reunirlas y que siempre ha de faltar una, declaro que es más seguro ser temido que amado [...] $Y$ ha de tenerse presente que un príncipe, y sobre todo un príncipe nuevo, no puede observar todas las cosas gracias a las cuales los hombres son considerados buenos, porque, a menudo para conservarse en el poder, se ve arrastrado a obrar contra la fe, la caridad, la humanidad y la religión. Es preciso, pues, que tenga una inteligencia capaz de adaptarse a todas las 
circunstancias, y que, como he dicho antes, no se aparte del bien mientras pueda, pero que, en caso de necesidad, no titubee en entrar en el mal [...] Trate, pues, un príncipe de vencer y conservar el Estado, que los medios siempre serán honorables y loados por todos (Maquiavelo, 1978, pp.29 у 31).

Por su parte, Thomas Hobbes quien fue un prolífico escritor, plantea la necesidad de centralizar el poder en manos de un soberano, en este caso, un rey con capacidades de imponer el orden y garantizar la seguridad. En Leviatán, libro publicado en 1651, Hobbes se refiere al poder con varios matices, entre los que destacan algunos porque delinean el poder como privilegio de unos cuantos que tienen la "honorabilidad" de imponer su voluntad sobre otros. En esta obra Hobbes privilegia el ejercicio del poder como un poder absolutista capaz de controlar a toda la población donde los súbditos le ceden todos sus derechos al soberano para que gobierne e imparta justicia. En Leviatán se legitima la búsqueda de riquezas y las ambiciones, y en aras de ello se ejerce el poder:

Por consiguiente, cualquiera que hace a un hombre amado o temido de otros, o la reputación de tal cualidad, es poder, porque constituye un medio de tener la asistencia y servicios de varios [...] Nobleza es poder, no en todo lugar, sino solamente en los Estados donde tiene privilegios: porque en tales privilegios consiste el poder [...] Dominio y victoria son cosas honorables porque se adquieren por la fuerza; y la servidumbre, por necesidad o temor, es deshonrosa [...] Ser distinguido, es decir, conocido por las riquezas, los cargos, las acciones grandes o la bondad eminente, es honorable porque constituye un signo del poder de quien es distinguido [...] La codicia de grandes riquezas, y la ambición de grandes honores, son honorables, como signos de poder para obtenerlas, La codicia y ambición de pequeñas ganancias o preeminencias es deshonrosa (Hobbes, 2005, pp.91,95,96,97).

La lista de autores que han trato el problema del poder es larga, algunos lo han hecho para legitimar el poder como dominación, mientras otros, para cuestionar ese fenómeno. En la historia de la filosofía política occidental podemos leer a múltiples pensadores que les ha preocupado el problema. Por ejemplo, en otro momento histórico distinto al de Maquiavelo y Hobbes, tenemos a 
Bakunin, uno de los fundadores del anarquismo, quien tiene una mirada muy crítica sobre el poder y el estado. Este teórico y militante político afirma incluso que el estado mismo es la organización del poder, y que todos los estados tienen en su mira la conquista de otros. En sus Obras Completas, en el volumen 4, titulado El principio del Estado (1871), se puede leer lo siguiente:

En el fondo, la conquista no sólo es el origen, es también el fin supremo de todos los Estados grandes o pequeños, poderosos o débiles, despóticos o liberales, monárquicos o aristocráticos, democráticos y socialistas también [...] Que ella fue el punto de partida de todos los Estados, antiguos y modernos, no podrá ser puesto en duda por nadie, puesto que cada página de la historia universal lo prueba suficientemente. Nadie negará tampoco que los grandes Estados actuales tienen por objeto, más o menos confesado, la conquista [...] Todo lo ridículo que se quiera, pero sin embargo es su sueño, como el sueño del más pequeño campesino propietario es redondear sus tierras en detrimento del vecino; redondearse, crecer, conquistar a cualquier precio y siempre, es una tendencia fatalmente inherente a todo Estado, cualquiera que sea su extensión, su debilidad o su fuerza, porque es una necesidad de su naturaleza. ¿Qué es el Estado si no es la organización del poder? Pero está en la naturaleza de todo poder la imposibilidad de soportar un superior o un igual, pues el poder no tiene otro objeto que la dominación, y la dominación no es real más que cuando le está sometido todo lo que la obstaculiza; ningún poder tolera otro más que cuando está obligado a ello, es decir, cuando se siente impotente para destruirlo o derribarlo [...] Por consiguiente, entre todos los Estados que existen uno junto al otro, la guerra es permanente y su paz no es más que una tregua (Bakunin, 1986, p.185).

Otro teórico que es referente para el estudio del poder es Max Weber, filósofo y sociólogo alemán, quien es considerado uno de los fundadores de la sociología moderna. Este pensador tiene una obra clásica titulada Economía y sociedad. Esbozo de sociología comprensiva, libro en el que manifestó sus ideas acerca de la política, la administración pública, y desde luego, la economía capitalista. En este texto, que fue publicado entre 1921 y 1922, Weber expresa su idea sobre el poder, y tal vez sea 
uno de los planteamientos más referenciados por los estudiosos de este fenómeno político, en dicha obra su autor hace explícita la relación entre poder, dominación y obediencia:

Poder significa la probabilidad de imponer la propia voluntad, dentro de una relación social, aun contra toda resistencia y cualquiera que sea el fundamento de esa probabilidad. Por dominación debe entenderse la probabilidad de encontrar obediencia a un mandato de determinado contenido entre personas dadas; por disciplina debe entenderse la probabilidad de encontrar obediencia para un mandato por parte de un conjunto de personas que, en virtud de actitudes arraigadas, sea pronta, simple y automática. El concepto de poder es sociológicamente amorfo. Todas las cualidades imaginables de un hombre y toda suerte de constelaciones posibles pueden colocar a alguien en la posición de imponer su voluntad en una situación dada. El concepto de dominación tiene, por eso, que ser más preciso y sólo puede significar la probabilidad de que un mandato sea obedecido (Weber, 2002, p.43).

John Holloway es un escritor contemporáneo nacido en Irlanda, pero radicado en México. Se trata de un marxista heterodoxo que le ha dado una sacudida a las ciencias sociales que abordan el tema del poder. Su libro clásico Cambiar el mundo sin tomar el poder. El significado de la revolución hoy, supuso un nuevo y acalorado debate en relación al estado, el poder y la revolución, discusión que alteró las visiones tradicionales del cambio social y político. En esta obra, Holloway hace una distinción entre poder-hacer y poder-sobre, resaltando que este segundo tipo de poder es un poder para la dominación. Además de puso sobre la mesa de debate los conceptos de antipoder y contrapoder. Al argumentar acerca del poder-sobre, indica que:

El poder-sobre es la ruptura del flujo social del hacer. Aquellos que ejercen el poder sobre la acción de los otros les niegan la subjetividad, niegan la parte que les corresponde en el flujo del hacer, los excluyen de la historia. El poder-sobre rompe el reconocimiento mutuo: aquellos sobre los que se ejerce el poder no son reconocidos [...] La historia se convierte en la historia de los poderosos, en la de aquellos que les dicen a los otros qué hacer. El flujo del hacer se convierte en un proceso antagónico en el que se niega el hacer de la mayoría, en el que algunos pocos se apropian del hacer de la mayoría [...] La ruptura del hacer siempre 
implica la fuerza física o su amenaza. Siempre existe la amenaza: "Trabaja para nosotros, de lo contrario morirás o sufrirás un castigo físico". Si la dominación consiste en que al hacedor se le robe lo hecho, ese robo es, necesariamente, un robo a mano armada. Pero lo que hace posible el uso de la amenaza o de la fuerza física es su estabilización o institucionalización en diversas formas, hecho que es crucial entender para comprender la dinámica y la debilidad del poder-sobre (Holloway, 2005, p.34).

Para Enrique Dussel, filósofo de la liberación, el poder como dominación es un poder fetichizado, concepto que este autor asocia a la idolatría, la corrupción y el envilecimiento. Para este teórico argentino mexicano hay un serio problema con este tipo de poder autorreferencial, ya que se le despoja al pueblo o a la comunidad de su capacidad para autodirigirse. En su obra 20 tesis de política, publicada por primera vez en 2006, se refiere al poder fetichizado como el poder de la Modernidad colonialista, de los imperios, los estados y los parlamentos liberales, ya que sus representantes ejercen el poder para proteger sus propios intereses y de las élites económicas. En sus derivaciones de la fetichización del poder, señala:

La fetichización del poder consiste en una "Voluntad-de-Poder" como dominio sobre el pueblo, sobre los más, sobre los débiles, sobre los pobres [...] La política es en este caso es el arte del ejercicio del poder sobre antagonistas a los que, en el mejor de los casos hegemónicamente, se les somete a la voluntad de las instituciones fetichizadas en favor de algunos miembros particulares de la comunidad, o, en el caso de los países poscoloniales (como los latinoamericanos), a Estados metropolitanos. El propio poder fetichizado, al no poder fundarse en la fuerza del pueblo, debe apoyarse sobre grupos que violentamente someten al pueblo -cuando el consenso dominante ha perdido efectividad para producir la obediencia de las masas- (Dussel, 2006, p.44).

En esta revisión de literatura político filosófica no puede faltar Michel Foucault, filósofo y sociólogo francés, quien en su producción intelectual también se ocupó de estudiar el tema del poder, aunque con una mirada distinta. Su teoría va más allá de entender el poder desde su personificación en el 
estado para plantear que se trata de un problema presente en toda relación social. Es lo que aquí se ha dicho en el sentido de que el ejercicio de poder puede provenir de grandes estructuras y sistemas, así como desde el tejido micro social, en donde se puede observar que puede haber dominación de género en una relación de pareja, o explotación laboral en un pequeño negocio, o bien, control patriarcal en una familia, así como manipulación de conciencia por algún líder carismático local. El establecimiento de relaciones jerárquicas dominadores-dominados está a la vuelta de la esquina. Pueden ser parte de macroestructuras y microestructuras que producen el mismo efecto dañando la dignidad humana y generando sufrimiento. De este modo, Foucault advierte de este fenómeno y se ocupa de desentrañar esos procesos microsociales, sin que ello implique negar la existencia de instituciones que forman parte de estructuras y sistemas desde donde se ejerce el poder dominante. En su texto El sujeto y el poder, publicado en 1982, Foucault se refiere a estas dos dimensiones en los siguientes términos:

Esto es verdad. Pero quisiera destacar el hecho de que el poder del Estado (y ésta es una de las razones de su fuerza) es una forma de poder individualizadora y totalizadora. Nunca, yo creo, en la historia de las sociedades humanas -ni en la vieja sociedad china- ha habido una combinación tan compleja de técnicas de individualización y procedimientos de totalización en el interior de las mismas estructuras políticas [...] Sin duda el objetivo principal en estos días no es descubrir lo que somos, sino rechazar lo que somos. Tenemos que imaginar y construir lo que podríamos ser para librarnos de este tipo de "doble atadura" política, que consiste en la simultánea individualización y totalización de las estructuras del poder moderno. Podría decirse, como conclusión, que el problema político, ético, social y filosófico de nuestros días no consiste en tratar de liberar al individuo del Estado, y de las instituciones del Estado, sino liberarnos del Estado y del tipo de individualización vinculada con él. Debemos fomentar nuevas formas de subjetividad mediante el rechazo del tipo de individualidad que se nos ha impuesto durante varios siglos [...] Regresemos a la definición del ejercicio del poder como una manera en que unos pueden estructurar el campo de acción posible de los otros. Así, lo que sería propio de una relación de poder es que ésta sería un modo de acción sobre acciones. Es decir, las relaciones de poder se encuentran 
profundamente arraigadas en el nexo social, y no constituyen "por encima" de la sociedad una estructura suplementaria con cuya desaparición radical quizá se pudiera soñar. En todo caso, vivir en una sociedad es vivir de modo tal que es posible que unos actúen sobre la acción de los otros. Una sociedad "sin relaciones de poder" sólo puede ser una abstracción. Lo cual, dicho sea de paso, hace políticamente mucho más necesario el análisis de lo que dichas relaciones son en una sociedad dada, de su formación histórica, de lo que las vuelve sólidas o frágiles, de las condiciones necesarias para transformar unas, para abolir otras [...] Puede verse por qué el análisis de las relaciones de poder en una sociedad no puede retrotraerse al estudio de una serie de instituciones, ni siquiera al estudio de todas aquellas que merecerían el nombre de "política". Las relaciones de poder están arraigadas en el tejido social [...] La dominación es una estructura global de poder cuyas ramificaciones y consecuencias pueden encontrarse a veces hasta en la trama más tenue de la sociedad; pero es al mismo tiempo una situación estratégica más o menos adquirida y solidificada en un enfrentamiento de largo alcance histórico entre adversarios (Foucault, 1982, pp. 8, 11, 17, $18,20)$.

Todos los autores citados se ocuparon en su momento del problema del poder, aunque cabe decir que no fue el único asunto que investigaron, ya que sus obras abordan otras circunstancias que también tienen una gran relevancia para el debate filosófico. Sin embargo, a lo largo de la historia estos pensadores son un referente para el análisis del poder político. A manera de síntesis, de lo que se citó de ellos se puede decir que todos observan el fenómeno del poder como un problema del cual se desprenden situaciones de opresión y sufrimiento. El poder-sobre se ha ejercido en todas partes y en todos los tiempos, siendo un asunto que se manifiesta en lo macroestructural, teniendo como centro el estado y sus instituciones, pero a su vez se plantea que ese poder-sobre también se concretiza en la cotidianidad de las relaciones sociales, formen parte o no, de sistemas y estructuras.

Maquiavelo y Hobbes son partidarios de centralizar el poder, ya sea para garantizar la creación y permanencia de los estados, o bien, para asegurar el orden y el control a partir del poder 
autorreferencial de un príncipe o rey. Bakunin advierte los riegos del estado, ya sea monárquico o liberal, dado que personifican el poder de una clase social y de unas élites que buscan proteger y ensanchar sus intereses a costa del sufrimiento de las mayorías. Por ello plantea la necesidad de abolir todo tipo de estado. En tanto Max Weber, asegura que el poder consiste en imponer la voluntad individual dentro de una relación social a pesar de las resistencias, logrando la obediencia de los demás, lo cual se puede lograr desde un estado, un sistema económico como el capitalismo o en una relación social dada que puede pertenecer a lo microsocial. Por tanto, la dominación consiste en la probabilidad de que un mandato sea obedecido, sea por la acción de la fuerza, la legalidad, el carisma u otros medios.

Holloway (2005) por su parte, plantea que el poder-sobre niega toda capacidad de hacer de la comunidad o de una sociedad que se encuentra sometida, ya que ese poder-sobre los niega. Dice que la historia se ha convertido en la historia de los poderosos, ya que han sido ellos los que en las diversas circunstancias históricas han oprimido a las mayorías. Señala que el poder como dominación siempre ha requerido su institucionalización y estabilización como mecanismos para legitimar ese tipo de poder. Dussel a su vez habla de la fetichización del poder, que asocia a la corrupción, es decir, que el poder le pertenece a la comunidad, pero cuando se delega y el representante se corrompe se convierte en un poder autorreferencial que protege intereses personales y de grupo. En este sentido, el estado y sus instituciones se fetichizan convirtiendo la política en la instrumentalización para el logro de los deseos individualistas y de camarilla. El poder se transforma para dominar, lo que sucede también en la economía.

Foucault, como ya se dijo, mira más allá del estado o el capitalismo, afirma que ahí hay poder para la dominación, sin embargo, resalta que ese problema no es exclusivo de macroestructuras, sino también hay una microfísica del poder, desde la cual se pueden analizar las relaciones sociales de dominación. En este sentido, expone que hasta en lo más tenue de la sociedad puede haber poder de unos sobre otros, por lo que el análisis debe contemplar ese complejo entramado social desde donde surgen poderes que oprimen y controlan. No se trata de mirar sólo la estructura y el sistema, sino también la relación social cotidiana donde unos asumen el 
rol de dominadores y otros de dominados. Por tanto, el estudio del poder debe contemplar este fenómeno de opresión, pero a su vez debe poner énfasis en el sujeto que puede y debe de-sujetarse de los procesos de hegemonía y control para convertirse en un actor que puede transformar las relaciones sociales.

Con las referencias anteriores de autores clásicos y no tan clásicos, se constata, desde un enfoque u otro, que el poder es un problema porque es ejercido para dominar, controlar y explotar. A lo largo de la historia, desde la antigüedad hasta nuestros días, se ha padecido el poder autorreferencial más que el poder social colectivo, constituyendo un hecho histórico generador de gravísimos padecimientos. El uso de la fuerza, de la legalidad, de la ideología y hasta del carisma, han sido medios utilizados para el control y la explotación. Es decir, el poder negativo destructivo sigue operando por distintas vías, sea la violencia o la legitimidad; sea a través de sistemas y estructuras, o a través de infinidad de relaciones sociales. Este poder-sobre, es acto consumado, es consecuencia y manifestación de necesidades, intereses y deseos egocentrados que pisotean la dignidad del otro, sea persona, comunidad, raza o cultura. Las evidencias están a la vista, y de ello, se dará cuenta en las siguientes líneas, aunque sea a manera de síntesis porque es casi infinita la lista de agravios que constituyen la gran estupidez humana del poder.

\section{El poder como dominación y sus estupideces}

La afirmación que se plantea en este texto es que el acto de dominar y someter a los otros es una estupidez porque se realiza a partir de visiones e intereses egocentrados que producen sufrimiento en quienes padecen dichas acciones. Pero ¿qué es la estupidez?, según algunos escritores que han reflexionado sobre este asunto señalan que es difícil tener una definición precisa al respecto, por consiguiente, han optado por asociar dicho fenómeno con una variedad de actitudes, percepciones y actos humanos. Por ejemplo, Antonio Fernández Vicente (2020) señala que la estupidez se refiere a la estrechez de miras, a una especie de egoísmo intelectual a través del cual se van imponiendo juicios y visiones del mundo donde prevalece sólo el punto de vista de la persona egocentrada. En este sentido, la estupidez es emparentada con la intolerancia y la ausencia de diálogo, condiciones 
que propician actitudes y actos que imponen la voluntad individual sobre cualquier otra consideración. "El estúpido es tosco y aun así fanfarrón. Niega la complejidad y difunde su simplicidad de forma dogmática" (Vicente, 2020). Esta acepción sobre la estupidez puede ser vinculada con el poder autorreferencial, ya que todo aquel que es poseedor de una voluntad de dominio impone su cosmovisión sobre la realidad sin importarle las consecuencias sociales y ambientales. Por tanto, no dialoga y efectivamente es intolerante. Los actos toscos para someter y depredar se realizan sin escuchar otras voces, otras necesidades, otros intereses u otros deseos, lo que importa es el beneficio propio, considerándolo como una verdad absoluta que no requiere ponerse a discusión con nadie.

Por su parte, Paul Tabori, en su obra Historia de la estupidez humana (1999), refiere que Alexander Feldmann, quien fue discípulo de Freud, llegó a contrastar la estupidez con la sabiduría, al indicar que "el sabio es el que conoce las causas de las cosas, mientras que el estúpido las ignora". Pero, podemos agregar en este mismo sentido que el estúpido no sólo ignora las causas sino también las consecuencias de sus acciones. Tabori, al citar a Loewenfield, dice que este doctor enfocó su análisis de la estupidez como un problema médico, y más que definir la estupidez se encargó de asociarla a ciertas formas de expresión, tales como que la estupidez es "una escasa capacidad de juicio, es magalomanía, vanidad y temeridad" (pp.8,14).

Este autor afirma que la estupidez está relacionada con la mayoría de las desgracias y debilidades humanas:

[...] pues la estupidez es como una luz negra, que difunde la muerte en lugar de la vida, que esteriliza en lugar de fecundar, que destruye en lugar de crear. Sus expresiones forman legión, y sus síntomas son infinitos [...] Todo esto poco importaría si el estúpido sólo pudiera perjudicarse a sí mismo. Pero la estupidez es el arma humana más letal, la más devastadora epidemia, el más costoso lujo. (Tabori, 1999, pp.18,22).

Este autor cuenta en su libro que Hugo von Castiglione, quien fue amo de un enorme imperio financiero e industrial en Europa, tenía una frase célebre que decía "nunca hagas mal 
innecesariamente. Hazlo en la medida que te de provecho y placer" (p. 67). Por lo que Tabori afirma que la estupidez es el resorte de las actitudes antisociales, y que la estupidez humana no tiene fin.

Por ello, los atropellos históricos contra grupos humanos y la naturaleza se repiten y constituyen la luz negra que difunden la muerte en lugar de la vida, que destruyen en lugar de crear. La estupidez, ciertamente, se ha convertido en el arma humana más letal y el más costoso lujo. De ahí que haya registros de actos de barbarie a lo largo de la historia y la evolución de las culturas, fenómenos que han causado un infinito sufrimiento y destrucción. En Historia de la estupidez humana, Tabori se refiere a fenómenos como la ambición por el oro, a partir de lo cual se han dado cruentos acontecimientos hasta nuestros días. Pero también escribe sobre la impartición torcida de justicia que han impartido tribunales, magistrados y jueces. Otras estupideces, según este autor, son el burocratismo y las actitudes de los burócratas en todo tipo de instituciones, así como los mitos y la magia que siguen muy presentes en el imaginario social. En este texto agregamos, siguiendo a Tabori, otro tipo de estupideces que también destruyen en lugar de crear, tales como la esclavitud, la guerra, la desigualdad, la depredación ambiental y un cúmulo de actos de dominación en la esfera microsocial, ejemplos de estupidez que son inadmisibles por los terribles daños ocasionados. Y es sobre este aspecto que se reflexiona en las siguientes líneas, la cuales dan cuenta de manera sucinta de los atentados contra la vida humana y no humana de esos actos que difunden la muerte en lugar de la vida.

\section{Estupideces trágicas}

\section{Esclavitud}

Una de las peores desgracias que ha padecido la humanidad a causa del poder como dominación es la esclavitud en sus muy variadas formas. Esclavitud hubo en la Antigüedad, en la Edad Media, en la Modernidad, y existe en el mundo actual. Marina y Rambaud (2019) señalan que:

[...]en el apogeo de su poder, el Imperio Romano necesitaba entre 250 y 400 mil esclavos al año. Los musulmanes fueron colosales compradores y vendedores de esclavos. En 
el siglo XIX había en la India ocho millones de esclavos. En tres siglos, más de quince millones de africanos fueron secuestrados y convertidos en mercancía. (pp.122,123).

Estos autores refieren que Fernando el Católico dio en 1510 el primer permiso para enviar esclavos negros en gran número al Nuevo Mundo para extraer oro de las minas de Santo Domingo. Esto sin olvidar que Cristóbal Colón traficó con esclavos indígenas del Caribe y que Hernán Cortés instauró un régimen esclavista en América con el consentimiento de la Corona Española.

La esclavitud no cesa, y hoy en el mundo globalizado hay registros de esclavitud moderna. En pleno siglo XXI se estima que en 2016 alrededor de 40.3 millones de personas fueron obligadas a trabajar contra su voluntad bajo amenazas, o viviendo en un matrimonio forzoso. Las estimaciones mundiales sobre este problema se centran en dos cuestiones de carácter global: el trabajo y el matrimonio forzosos. Según la Organización Internacional del Trabajo (OIT), la estimación del trabajo forzoso:

[...] abarca el trabajo en la economía privada (formas de trabajo forzoso impuestas por individuos, grupos o empresas privadas, en todos los sectores con excepción de la industria sexual comercial); la explotación sexual forzosa de adultos y niños; y el trabajo forzoso impuesto por el Estado. (Organización Internacional del Trabajo, 2017).

De estos 40.3 millones de víctimas, 24,9 millones de personas estaban sometidas a trabajo forzoso. Esto equivale a decir que estaban obligadas a trabajar, bajo amenazas o coacción, como trabajadores domésticos, como obreros en el sector de la construcción, en fábricas clandestinas, en explotaciones agrícolas, en buques pesqueros, y en otros sectores, así como en la industria sexual. La obligación de trabajar estaba impuesta por individuos o grupos del sector privado, o bien por autoridades del Estado. En muchos casos, los productos que fabricaban y los servicios que prestaban formaban parte de canales comerciales en apariencia legítimos. Las personas sometidas a trabajo forzoso producen parte de los alimentos que consumimos y de la ropa que usamos, y limpian los edificios en los que muchos vivimos o trabajamos. Por otra parte, 15.4 millones de personas vivían en un matrimonio forzoso al cual no habían prestado su consentimiento. Es decir, soportaban una 
situación que implicaba haber perdido su autonomía sexual y a menudo suponía la prestación de tareas bajo el pretexto de 'matrimonio'. (OIT, Walk Free y OIM, 2017, pp. 7, 8).

Si antes la esclavitud se realizaba como parte del sistema colonial o por la existencia de imperios, hoy la esclavitud moderna es parte del funcionamiento del capitalismo, estados totalitarios y microestructuras sociales como familias patriarcales. Otros datos que proporciona la OIT tienen que ver con la prevalencia de este fenómeno, por ejemplo, se indica que, en 2016, 5.4 de cada mil personas de todo el mundo eran víctimas de esclavitud moderna. Las mujeres y las niñas representaban el 71 por ciento de esa esclavitud que hoy se ejerce como acto de dominación. La servidumbre por deudas afectaba a la mitad de todas las víctimas de trabajo forzoso impuesto por actores privados. Al situar este problema en términos geográficos, la OIT advierte que la esclavitud moderna se ha expandido por todo el planeta, por lo que se localiza en África, Asia Central, Asia del Pacífico, Europa, América Latina y Norteamérica.

\section{La guerra}

Otra gran estupidez resultado del ejercicio de poder autorreferencial de individuos y grupos es la guerra, que al igual que la esclavitud, sigue existiendo en pleno siglo XXI. Se puede indicar que las guerras se han producido entre estados o al interior de estos. Su magnitud ha sido local, nacional, regional e incluso global. Las motivaciones siempre son las mismas, expandir el dominio y someter a los otros. En el recuento de esta estupidez se puede señalar que ha habido guerras por intereses políticos, económicos, ideológicos, racistas, delincuenciales y hasta religiosos. Todas han producido tragedias y se pueden contar por millones las víctimas que han muerto por las ambiciones humanas. Por regla, los estados más fuertes le declaran la guerra a los más débiles, aunque también ha habido circunstancias en que ciertos estados se atreven a hacerle la guerra a los más poderosos. La cultura bélica nos acompaña desde mucho tiempo atrás, y sus resultados están a la vuelta de la esquina con la proliferación de armas atómicas en todos los continentes, cuya existencia pone en riesgo la viabilidad de la vida en el planeta. 
Marina y Rambaud (2019), indican que "el poder europeo, basado en la industria, en la ciencia y en la tecnología, incluida la militar, acabó dominando el mundo en el siglo XIX y parte del siglo XX" (pp. 392, 393). Sin embargo, no se puede dejar de lado que los campeones de la guerra y el poder en el siglo $\mathrm{XX}$ y siglo $\mathrm{XXI}$, son los Estados Unidos. Su poderío es inigualable, ya que su presencia militar y su capacidad de hacer la guerra es altamente destructiva, como se pudo constatar en Hiroshima y Nagasaki. Además, su enorme capacidad tecnológica los coloca en una posición dominante para destruir en minutos objetivos que consideran un peligro para sus intereses y los de sus aliados. Si de poder global militar se habla, quien encabeza la lista es sin duda Norteamérica.

La guerra bien puede entenderse como la expansión del poder, ya sea en su dimensión económica o política, e incluso religiosa, como ya se mencionó. El afán de conquistar nuevos territorios y el deseo de nuevos mercados y recursos, son los resortes que impulsan las acciones bélicas, y eso viene desde mucho tiempo atrás. El imperialismo chino, así como el imperialismo europeo en su versión colonialista, capitalista y comunista, y el imperialismo estadounidense son los representantes históricos de la expansión, el saqueo y la guerra. Si bien es cierto que las actuales confrontaciones en diversos países tienen una dinámica local que van más allá de las guerras convencionales, no se puede ignorar que detrás de los actores en disputa siempre hay fuerzas supranacionales que apoyan a uno u otro bando. Es decir, la geopolítica siempre está presente en la guerra, ya que los territorios y sus recursos son de gran interés para las grandes potencias.

Un recuento de Naciones Unidas indica que, en 2016, la cantidad de países que se vieron afectados por conflictos violentos alcanzó el nivel más alto registrado en casi 30 años. Por otra parte, el organismo internacional advierte de un desmantelamiento de la estructura de control de armamentos que le ha dado cierta estabilidad al mundo en los últimos decenios, lo que vuelve a poner en riesgo la supervivencia de la humanidad con la proliferación de todo tipo de armas. Señala que en la actualidad existen alrededor de 14 mil armas nucleares instaladas en diversas regiones del planeta, lo que sigue siendo un gran peligro para la vida humana y el resto de las especies (ONU, 2020). 


\section{Desigualdad y pobreza}

Desigualdad y pobreza son dos realidades que tienen que ver con los diversos sistemas económicos y políticos preexistentes y presentes que se han estructurado a partir del ejercicio de poder autorreferencial. La existencia de países altamente industrializados y poderosos, así como de naciones con fuertes atrasos económicos y sociales, son resultados de una historia de dominación global pero también nacional donde unas élites imponen sus intereses sobre las mayorías. El escenario internacional contemporáneo es revelador de ello, el protagonismo económico y tecnológico del llamado Grupo de los 7 (los siete países más industrializados del mundo: Estados Unidos, Alemania, Gran Bretaña, Canadá, Francia, Italia y Japón), sin dejar de mencionar a China y Rusia, en la conducción de la globalización, es un hecho inobjetable. Pero, por otra parte, el protagonismo político de estas naciones, particularmente de sus grupos de poder también es innegable en el contexto actual. Se puede asegurar que este conjunto de países y sus poderosas élites gobiernan el proceso global con la imposición de sus políticas hacia el resto del mundo.

Su poder reside en sus estados, en sus trasnacionales y sus instituciones como el Fondo Monetario Internacional (FMI), el Banco Mundial (BM) y la Organización Mundial del Comercio $(\mathrm{OMC})$, así como por su enorme influencia en la propia Organización de las Naciones Unidas (ONU), cuyo Consejo de Seguridad Permanente está conformado por Estados Unidos, China, Rusia, Francia y Reino Unido. Además de contar con su brazo armado que es la OTAN, la cual reafirma no sólo la hegemonía política, económica y tecnológica, sino también la militar de ese gran bloque de poder que se articula y se interrelaciona. En el contexto internacional existe pues un poder estructurado que conduce el destino del capitalismo contemporáneo y que ha creado una estructura supranacional a la que está sometida el resto del mundo. Dicha estructura supranacional penetra los estados nacionales imponiendo el modelo económico y político que deben seguir, por ello, se continúa profundizando la desigualdad global, toda vez que el sistema capitalista responde a una lógica de enriquecimiento corporativo y elitista que privilegia la estructura supranacional y los 
grupos hegemónicos de cada país. El problema es mayúsculo, ya que, por ejemplo, en 2019, los 2,153 multimillonarios del mundo poseían más riqueza que 4,600 millones de personas.

Según Oxfam Internacional (2020) esta enorme brecha que se ve reflejada en los datos anteriores es consecuencia "de un sistema económico fallido y sexista que valora más la riqueza de una élite privilegiada, en su mayoría hombres" (p.2). De acuerdo con esta organización mundial que trabaja en contra de la pobreza y la desigualdad:

[...] los 22 hombres más ricos del mundo poseen más riqueza que todas las mujeres de África. Estos ejemplos de riqueza extrema conviven con un enorme nivel de pobreza. Según las estimaciones más recientes del Banco Mundial, prácticamente la mitad de la población mundial vive con menos de 5.50 dólares al día" (Oxfam, 2020, p.7).

Esta institución se refiere al capitalismo como un modelo defectuoso que no distribuye la riqueza, sino que la acumula en enormes cantidades en manos de élites ricas que se benefician en parte por la explotación del trabajo de mujeres y niñas. Planteamiento que coincide con lo aquí expuesto, y más cuando señalan que en lo alto de la economía global se encuentran grupos poderosos con fortunas inimaginables, que van incrementando exponencialmente su riqueza.

En su informe de 2020 titulado Tiempo para el cuidado. El trabajo de cuidados y la crisis global de desigualdad, esta organización señala que la acumulación de la riqueza y su consecuente desigualdad se asocia a "la enorme reducción de la tributación de las grandes fortunas y empresas, debido tanto a la reducción de los tipos impositivos como a la evasión fiscal deliberada" (p.11). Oxfam expone unos datos reveladores de lo anterior, al indicar que tan sólo el 4\% de la recaudación fiscal mundial procede de los impuestos sobre la riqueza, además señala que las grandes fortunas eluden hasta el $30 \%$ de sus obligaciones fiscales, situación que propicia las mejores condiciones para la acumulación y la desigualdad, ya que lo anterior afecta en muchos sentidos a los estados, sus sociedades y la masa de trabajadores que labora bajo condiciones salariales precarias. 
La desigualdad es una de las graves problemáticas que enfrenta la humanidad, fenómeno que revela la imposición de un poder económico y político, pero también de género, ya que a nivel mundial se estima que los hombres poseen un $50 \%$ más de riqueza que las mujeres, por lo que la riqueza extrema se asienta también sobre el sexismo, esto, a decir de Oxfam. Esta organización refiere que la desigualdad económica se ha construido sobre la desigualdad de género, ya que la mayoría de las personas situadas en la parte más baja de la pirámide económica son mujeres. En el capitalismo, que representa una cultura de poder dominante, las mujeres y las niñas tienen más probabilidades de ocupar puestos de trabajo precarios y mal pagados con respecto a los hombres, constatando con ello la existencia de una desigualdad producida por un sistema con sello de darwinismo social donde los más fuertes someten a las mayorías pobres. Como lo indica el organismo, "la riqueza extrema es síntoma de que vivimos en un sistema económico fallido" (Oxfam, 2020, p. 23).

\section{El poder-sobre la naturaleza}

A fines del 2020 el secretario general de la Organización de las Naciones Unidas (ONU) (2020), Antonio Gutiérrez, acusó que la humanidad libra una guerra contra la naturaleza, esto a propósito de dos informes científicos, uno de la Organización Meteorológica Mundial y el otro del Programa de las Naciones Unidas para el Medio Ambiente, organismos que dan cuenta de la devastación climática producida por la acción humana. En un discurso pronunciado en la Universidad de Columbia, en Nueva York, el jefe de la ONU aseveró que "nos enfrentamos a una pandemia devastadora, nuevos máximos de calentamiento global, nuevos puntos bajos de degradación ecológica y nuevos reveses en nuestro trabajo hacia los objetivos globales para un desarrollo más equitativo, inclusivo y sostenible" (CNN, discurso personal, 2 de diciembre de 2020). En los dos informes referidos se proporcionan datos sobre la grave crisis ambiental que padece el mundo, que va desde la desaparición acelerada de bosques, hasta la sobreexplotación del mar, la emisión incontenible de dióxido de carbono a la atmósfera, el calentamiento global y la desaparición de especies. 
Lo anterior coincide con otros muchos informes que advierten de los profundos riesgos que ha ocasionado la actividad industrial depredadora. Por ejemplo, la famosa Carta de la Tierra, que fue elaborada a principios de la década de los noventa y que tuvo respaldo institucional de la UNESCO para ser publicada en 2003 con fines educativos, donde se indica que las bases de la seguridad global están amenazadas. Uno de sus autores, Leonardo Boff (2020), señala que:

[...] estos peligros solamente serán evitados si mudamos la producción y el modelo de consumo. Este giro total civilizatorio exige la voluntad política de todos los países del mundo y la colaboración sin excepción de toda la red de empresas transnacionales y nacionales de producción, pequeñas, medianas y grandes. (Párr. 12).

Este planteamiento implica desde la perspectiva del poder, que los corporativos cambien de cosmovisión para que entiendan que la sobreexplotación y el lucro generan profundas consecuencias en la vida del planeta. De igual modo, se debe corregir el hiperconsumo de las sociedades modernas, las cuales contribuyen con sus acciones desenfrenadas a la devastación de los recursos naturales. Por ello, lo que dice Boff tiene veracidad, al indicar que:

[...] el gran peligro reside en la lógica del sistema del capital globalmente articulado. Su objetivo es lucrar lo más posible en el más corto tiempo posible, con una expansión cada vez mayor de su poder, flexibilizando legislaciones que limitan su dinámica. Él se orienta por la competencia y no por la cooperación, por la búsqueda del lucro y no por la defensa y promoción de la vida (Boff, 2020).

\section{Conclusiones}

El poder como dominación continúa existiendo en la historia de las civilizaciones y se ha convertido en una profunda huella destructiva debido a sus efectos sobre la vida humana y de otras especies. De esto han dado cuenta numerosos filósofos y estudiosos de las ciencias sociales, como se puede constatar en este texto. Aunque la evidencia mayor se encuentra en los acontecimientos sucedidos 
en todas partes del mundo y en todos los tiempos. Si la estupidez es representada como una imagen de luz negra que difunde la muerte y destruye en lugar de crear, convirtiéndose en un arma humana letal y devastadora, entonces, no cabe duda que el poder dominante es una gran estupidez porque a lo largo de la historia ha producido un expandido sufrimiento en todas las sociedades.

Ese tipo de poder ha sido el causante de millones de esclavos, de millones de muertes, de millones de pobres y de la destrucción de la naturaleza. La avaricia, la egocentricidad y la insolidaridad son conductas humanas que configuran los clasismos sociales elitistas y no elitistas desde donde brota el poder de dominación, constituyéndose así en una cultura naturalizada a la que aspiran muchos porque ahí encuentran su sentido de ser. Dicha cosmovisión de vida modela el ideal capitalista, por lo que esa cultura seguirá reproduciéndose mientras siga existiendo dicho sistema. El gran desafío humano se encuentra en generar otro tipo de perspectivas donde se valore y se proteja la vida de todas las personas y de la naturaleza misma, un constructo cultural donde prevalezcan otros valores y otros razonamientos no centrados en el tener, en el acumular, en el oprimir y en la estratificación social. A lo largo de la historia eso ha sido muy complicado porque ni las religiones, ni los derechos humanos, ni la filosofía social, ni el comunismo y ni el liberalismo lo han logrado. Sin embargo, mientras siga habiendo voces y movimientos emancipadores, la aspiración de justicia e igualdad seguirá destellando.

\section{Referencias}

Bakunin, M. (1986). Obras Completas, volumen 4, El principio del Estado (1871) (versión electrónica). Madrid: Las Ediciones de La Piqueta

Boff, L. (2020). ¿Es posible el fin de la especie humana? (I y II). Obtenido el 05 de octubre de 2020, de Servicioskoinonia.org: http://servicioskoinonia.org/boff/articulo.php?num=1003

Diccionario de la Lengua Española (2020). Obtenido el 10 de agosto de 2020, de Real Academia Española: https://dle.rae.es/poder

Dussel, E. (2006). 20 tesis de política. México: Siglo XXI Editores, Centro de Cooperación Regional para la Educación de Adultos en América Latina y el Caribe 
Fernández, A. (2020). ¿Qué es la estupidez? Obtenido el 29 de julio de 2020, de The Conversation: https://theconversation.com/que-es-la-estupidez-142471

Foucault, M (1982). El sujeto y el poder. En Revista Mexicana de Sociología, vol. 50, No. 3, 3-20.

Hobbes, T. (2005). Leviatán I. México: Ediciones Gernika

Holloway, J. (2005). Cambiar el mundo sin tomar el poder. El significado de la revolución hoy (versión electrónica). Venezuela: Vadell Hermanos Editores.

Maquiavelo, N. (1978). El Príncipe. México: Editorial Porrúa

Marina, J. y Rambau, J. (2019). Biografía de la Humanidad. Historia de la evolución de las culturas. México: Ariel

Organización Internacional del Trabajo, Fundación Walk Free, Organización Internacional para las Migraciones (2017). Estimaciones mundiales sobre la esclavitud moderna: trabajo forzoso y matrimonio forzoso - Resumen ejecutivo (versión electrónica). Ginebra: Oficina Internacional del Trabajo.

Organización de las Naciones Unidas (2020). Forjando nuestro futuro juntos. Obtenido el 25 de septiembre de 2020, de Naciones Unidas: https://www.un.org/es/un75/new-era-conflictand-violence

Oxfam Internacional (2020). Tiempo para el cuidado. El trabajo de cuidados y la crisis global de desigualdad (Resumen) (versión electrónica). Gran Bretaña: Oxfam Internacional

Tabori, P. (1999). Historia de la estupidez humana (versión electrónica). Editado por elaleph.com.

Weber, M. (2002). Economía y Sociedad. Esbozo de sociología comprensiva. España: Fondo de Cultura Económica 